\title{
Bridging the Gap Between Genomics and Education
}

\author{
Stephen A. Petrill ${ }^{1}$ and Laura M. Justice ${ }^{1}$ \\ 1 The Ohio State University
}

\section{Abstract}

Despite several decades of research suggesting the importance of both genetic and environmental factors, these findings are not well integrated into the larger educational literature. Following a discussion of quantitative and molecular genetic methods, this article reviews behavioral genetic findings related to cognitive and academic skills. This literature suggests that (a) the relative importance of genes and environments varies developmentally; (b) genetics, and to a lesser extend the environment, account for a substantial portion of the covariance within and across academic domains; and (c) some forms of disability are qualitatively different from the population, whereas others constitute the lower end of a continuum of ability. Following a discussion of the strengths and limitations of current behavioral genetic research and intervention research, we then discuss the ways in which understanding gene -environment interplay can be used to develop better definitions of learning impairment and better explain the substantial variability in response to intervention.

For over a century, it has been well established that mental abilities run in families (e.g., Galton, 1869; Orton, 1925). Reviews of twin and adoption studies have yielded consistent findings for both genetic and environmental influences on intelligence (Bouchard \& McGue, 1981; Chipuer, Rovine, \& Plomin, 1990; Erlenmeyer-Kimling \& Jarvik, 1963; Plomin \& Spinath, 2004), language ability (see Bishop, 2006), math skills (see Petrill \& Plomin, 2007), and reading ability (Foch, DeFries, McClearn, \& Singer, 1977; Matheny, Dolan, \& Wilson, 1976; Stevenson, Graham, Fredman, \& McLoughlin, 1987; Zerbin-Rüdin, 1967). Concerning the latter, genetic effects have been found for such reading-related skills and abilities as phonological awareness/decoding, comprehension, spelling, orthographic knowledge, and rapid automatized naming (see Compton, Davis, DeFries, Gayan, \& Olson, 2001; Gayan \& Olson, 2001, 2003; Knopik, Alarcon, \& DeFries, 1998; Olson, Forsberg, \& Wise, 1994; Olson, Gillis, Rack, DeFries, \& Fulker, 1991). In general, roughly $30 \%$ to $60 \%$ of the differences in these outcomes can be attributed to genetic variance, with the remaining variance due to nongenetic effects. As described more fully by Grigorenko, Haworth, Schulte-Körne, Willcut, and their colleagues in this special issue, molecular genetic studies have begun to identify DNA markers that account for statistically significant variance in reading and reading disability, and studies employing neuropsychological designs have begun to describe brain-behavior relationships.

\begin{abstract}
Although the field of educational research and practice generally recognizes that students' educational outcomes are influenced by both genetic and environmental influences, these findings have yet to be well integrated into the larger empirical and theoretical literature examining how educationally related outcomes develop, why children learn differently, and how interventions can be put in place to prevent or remediate learning problems. Therefore, the purpose of this manuscript is threefold. Following a brief overview of methods and assumptions, we will describe key general points from the fields of behavioral genetics and
\end{abstract}

Address correspondence to Stephen A. Petrill, Department of Human Development and Family Science, The Ohio State University, 1787 Neil Avenue, Columbus, OH 43210; petrill.2@ osu.edu. 
molecular genetics related to cognitive and academic skills. We will also describe the implications of these points for future studies examining educational development and educational intervention, drawing out why it is necessary for educational research to better take on board genetically and biologically sensitive designs.

\section{GENETICALLY SENSITIVE DESIGNS}

Like almost all research designs involving humans, genetically sensitive designs involve the study of variation among outcomes of interest. Quantitative genetic methods typically employ twin and adoption designs to examine whether family members who are genetically more similar are also more similar in measured outcomes (called phenotypes). In essence, quantitative genetic designs are a special case of multilevel modeling (see Guo \& Wang, 2001). Individual twins are nested within families. If there is familial resemblance, then fixed effects (family level) variance will be significant. To the extent that identical twins are more similar than fraternal twins, random effects will be smaller in identical relative to fraternal twins, suggesting greater familial resemblance. If identical twins are more similar to fraternal twins, then genetic influences are inferred (often called heritability or $h^{2}$ ). The same logic applies when comparing biologically related family members to adoptive family members. Shared environments (or $c^{2}$, those environments both inside and outside of the home that make family members similar) are inferred to the extent that genetic similarity does not lead to greater similarity in observed educational performance or behavior.

Univariate genetic methods examine the familial relationships on the same outcomes. Multivariate genetic methods examine familial relationships on different outcomes. For example, if the cross-sibling correlation between phonological awareness and word identification is higher in identical pairs than in fraternal pairs, then it is assumed that phonological awareness and word identification are influenced by genetic covariance. These designs can also be used to examine developmental stability and instability by comparing the cross-sibling, cross-time correlation.

Quantitative genetic designs offer a powerful mechanism to infer the statistical etiology of individual differences, whether they co-occur in families and whether this co-occurrence is mediated by genetics or environment. These designs also offer a powerful tool to study etiology of the environment - whether the environments most important for individual differences operate between or within families. This literature suggests four key findings for the study of cognitive and educational outcomes. First, as described above, both genetic and environmental influences appear to be important to individual differences in general cognitive ability, reading performance, math performance (see Plomin \& Kovas, 2005 for a review; also Fisher \& DeFries, 2002). However, an important second finding is that the magnitude of these effects appears to vary developmentally. In the case of reading, cross-sectional studies using children drawn from a wide age range have shown that the component processes of reading such as phonology, fluency, and orthographic skills are correlated largely via genetic pathways (e.g., Davis, Knopik, Olson, Wadsworth, \& DeFries, 2001; Gayan \& Olson, 2001, 2003). However, our own data (Petrill, Deater-Deckard, Thompson, \& DeThorne, 2006) and the data of others (Byrne et al., 2002; Harlaar, Spinath, Dale, \& Plomin, 2005) suggest age-related differences in genetic and shared environmental effects. In particular, studies have suggested significant shared environmental influences for content-based skills such as word knowledge (Byrne et al., 2002) and phonological awareness (Petrill et al., 2006), a finding not reported in crosssectional studies of older children, which show strong genetic and negligible shared environmental effects. General cognitive ability yields similar findings. Shared environmental influences are significant in early childhood but drop to zero by adolescence (see Boomsma, 1993; McCartney, Harris, \& Berneiri, 1990; McGue, Bouchard, Iacono, \& Lykken, 1993; Plomin, 1986; Plomin, Fulker, Corley, \& DeFries, 1997; Wilson, 1983). In fact, this pattern of 
results is prevalent in most behavioral outcomes (see Plomin, DeFries, McClearn, \& McGuffin, 2001). The nonshared environment (including error) remains significant throughout the life span.

Third, multivariate genetic analyses suggest that genetic covariance plays an important role in the observed covariance within and across cognitive and academic domains. For example, early multivariate genetic analyses involving twin and adoption studies found consistent evidence for genetic overlap between different types of academic achievement such as reading ability, math ability, and language ability (Plomin \& DeFries, 1979; see Petrill \& Plomin, 2007; Plomin $\&$ Kovas, 2005, for a review). These studies also have suggested that the genetic covariance among cognitive skills becomes increasingly important with age (Bartels, Reitveld, Van Baal, \& Boomsma, 2002; Bishop, Cherny, \& Hewitt, 2003; Cherny et al., 1994; Fulker, Cherny, \& Cardon, 1993; Petrill, 2003). Furthermore, genetic factors influence a significant proportion of the longitudinal covariance in cognitive (Cherny et al., 1994; Petrill et al., 2004) and reading skills across time points (Byrne et al., 2005; Harlaar et al., 2005; Petrill, Deater-Deckard, Thompson, Schatschneider, \& DeThrone, 2007; Wadsworth, Corley, Hewitt, Plomin, \& DeFries, 2002).

It must be stressed, however, that different academic domains cannot be reduced to a common set of genes. For example, as described more fully by Grigorenko and colleagues, DNA markers for reading disability do not predict general cognitive ability deficits. In the same vein, the quantitative genetic evidence described above also provides some evidence for genetic specificity, particularly for mathematics (e.g., Kovas, Harlaar, Petrill, \& Plomin, 2005). Finally, the issue of genetic overlap and specificity is also tied to the complexity of the tasks used to measure different cognitive domains; a measure of math problem solving also includes some of the same demands as a task tapping reading comprehension. Evidence suggests that genetic influences are important to both covariance and specificity.

Fourth, quantitative genetic studies yield provocative findings concerning the relationship between ability and disability. For decades, clinical research has identified relatively rare, qualitatively distinct diagnostic categories involving cognitive and academic disabilities. Subsequent research has gone on to identify genetic factors underlying these diagnoses - for example, Down syndrome has been associated with a duplication of Chromosome 21 (Leguene, Gautier, \& Turpin, 1959). Conversely, the psychometric tradition has typically viewed difficulties in cognitive and academic skills as the lower tail of a quantitative distribution of performance. According to this model, low performance in most individuals is not due to a single cause but to a large set of risk and protective factors that operate across a distribution of ability.

It has been largely assumed that more severe, rare, and pervasive deficits emblematic of qualitative diagnostic categories possess a strong biological component but that the less severe, more common difficulties that fall into the quantitative psychometric tradition are influenced by the environment (see Zigler \& Hodnapp, 1986). However, the "environment-only" assumption does not appear to be supported by the behavioral genetic data. This approach has been largely examined using DeFries-Fulker (DF) extremes analysis (DeFries \& Fulker, 1985, 1988). First, a group of twins (called probands) is selected on the basis of a threshold of disability. The mean performance of these probands will be substantially below the unselected population mean. Familial resemblance is quantified by examining the mean performance of the cotwins. The cotwin mean will be similar to the proband mean to the extent that performance is familial. In contrast, the cotwin mean will regress back to the unselected population mean to the extent that cotwins are uncorrelated with their proband siblings on the outcome of interest. If identical cotwins are more similar to probands than fraternal cotwins, then genetic influences are inferred. The resulting statistic, called group heritability $\left(h_{\mathrm{g}}^{2}\right)$, estimates the 
extent to which the mean difference between the disabled group and the unselected population is due to genetic factors. Shared environmental influences are inferred to the extent that identical and fraternal cotwins are equal (called $c_{\mathrm{g}}^{2}$ ).

In general, behavioral genetic studies have suggested that both genetic and environmental influence are important to understanding why groups with no known diagnosis or no known genetic or environmental risk factors nevertheless fall below a certain threshold of functioning. Thus is the case for general cognitive ability (Petrill et al., 1997; Plomin et al., 2001; Plomin \& Thompson, 1993; Saudino, Plomin, Pedersen, \& McClearn, 1994) but also for readingrelated outcomes (Fisher \& DeFries, 2002) as well as mathematics (Haworth, Kovas, Petrill, $\&$ Plomin, 2007; Kovas, Petrill, Haworth, in press \& Plomin).

More provocatively, if $h_{\mathrm{g}}^{2}$ in the disability group is different from $h^{2}$ in unselected ability, then we can conclude that there is discontinuity in how genes and environments impact disability versus ability. In contrast, if disabled and unselected groups are similar, then there are two possible interpretations. First, those genetic and environmental influences underlying developmental disability are continuous with those in the unselected population. In other words, disability is the tail of the normal range of ability. Another possible interpretation is that different genes and environments are operating, but their relative importance is similar for disability and ability. The studies described above have almost universally found that $h^{2}$ is similar in magnitude to $h_{\mathrm{g}}^{2}$.

To summarize, genetic influences on general cognitive ability, reading, math, language, and the cognitive processes underlying these domains are statistically significant, and are important to stability within and across domains, as well as across measurement occasions. Shared environmental influences are statistically significant in early childhood but decline to zero by adolescence. Nonshared environmental influences (and error) remain significant throughout the life span. Finally, although qualitatively distinct categories account for some cases of impairment, the large majority of individuals with low performance appear to emanate from the same distribution of genetic and environmental influences operating across the range of ability.

\section{MOLECULAR GENETICS}

The quantitative genetic approaches described above are useful but do not identify the set of genes or measured environmental characteristics that underpin this variability. Molecular genetic designs, on the other hand, quantify the relationship between variance in DNA markers (called polymorphisms) and behavioral outcomes. Eloquently described by Grigorenko and colleagues in the case of linkage designs, the comparison is whether familial similarity between a particular version of DNA (called an allele) in a certain place in the genome (called a locus) correlated with familial similarity in phenotypes. In the case of association designs, the comparison is whether the presence of a particular form of a DNA marker is correlated with performance on measured outcome in unrelated members of a population.

In addition to the issues highlighted by the other contributions to this special issue, we wish to highlight two key points related to the discussion of ability and disability described above. First, known major genetic effects do not cause most cases of mental impairment, reading disability, math disability, or language impairment. Major genetic effects are characterized by a single mutation or small number of mutations that explain a large proportion of the variance in an outcome. In essence, if a child has a particular genotype, he or she is highly likely to also exhibit a particular outcome. This One-Gene-One-Disorder hypothesis (see Plomin, Owen, \& McGuffin, 1994) has shed important light on the underpinnings of certain relatively rare clinical 
syndromes associated with developmental disabilities. For example, Rett syndrome is a disorder associated with a period of 6-18 months of normal development, followed by a slowing and then complete loss of acquired cognitive and motor skills, resulting in a loss of speech, autistic features, and mental retardation. Rett syndrome has been localized to a set of mutations in the MECP2 gene located in the long arm of the $\mathrm{X}$ chromosome (Amir et al., 1999). However, these mutations occur in only 1 out of 15,000 individuals. Considering that autism-spectrum behaviors occur in 1:150 individuals (Centers for Disease Control, 2007), the presence of genes associated with Rett syndrome, although an important determinant of autistic features in some children, does not shed light on the majority of children with autistic features. The same logic applies for other forms of mental impairment. For example, Zechner et al. (2001) presented over 200 genetic mutations associated with mental retardation and as of 2007, 800 polymorphisms associated with "mental retardation" were listed in the Online Mendelian Inheritance in Man database. However, these polymorphisms tend to be very rare and together account for a minority of cases of mental retardation. As noted in the other contributions to this special issue, the same appears to be the case for reading, math, and language problems. Major genetic effects do not carry the day when explaining variance in educational outcomes across the population nor do they explain most instances of low performance.

Instead, genetic mechanisms for most educational outcomes in most people operate as risk factors that account for relatively small proportions of variance when examined across the entire population (see Plomin, Kovas, \& Haworth, 2007; also Grigorenko, Haworth, SchulteKörne, Willcutt, and their colleagues in this special issue). As described in the other contributions to this special issue, DNA markers related to complex cognitive and academic outcomes are very small in effect size, ranging from $<1 \%$ to $5 \%$ of the variance. Some of these DNA markers operate independently (e.g., specific language impairment) but some tend to promote covariance across different educational outcomes (e.g., Haworth et al., this issue). Taken together, quantitative and molecular genetic studies suggest that (a) genetic influences may be important to most cognitive and educational outcomes; (b) genetic influences may be important to the covariance across outcomes and across time; (c) genetic effects likely operate as risk/protective factors across the population; and (d) most instances of developmental disability, the ones that lie outside of clinical diagnoses, are influenced by the same genes that operate across the continuum of ability.

\section{Implications}

The strong and consistent evidence for genetic influences on educational outcomes opens up important empirical (and yet unanswered) questions concerning how the process of educating children is related to the substantial genetic variability related to educational performance. It would be erroneous to conclude from the genetic literature that environment does not matter. On the contrary, findings from the field of genetics open up exciting new possibilities for better understanding how environments operate and how they influence individual differences in education, including students' educational outcomes. The literature has approached gene environment influences in two ways. First, researchers have attempted to identify measures of the environment that constitute the shared family environment (or $c^{2}$ ) estimated by twin and adoption designs, controlling for genetic differences (see Figure 1). For example, reading success is associated with reading-related knowledge and skills children have acquired prior to coming to school(see McCardle, Scarborough, \& Catts, 2001) and the quality of the home environment during school (e.g., Molfese, Molfese, Key, \& Kelly, 2003). Several investigators (e.g., Briggs \& Elkind, 1977;Dunn, 1981;Rescorla, Hyson, Hirsh-Pasek, \& Cone, 1990) have suggested that parental attitudes toward and expectations about reading and school are important predictors of reading precocity. Others have pointed to the importance of the "Family Literacy Environment" (see Christian, Morrison, \& Bryant, 1998) — the provision of varied and frequent contact with experiences associated with literacy. For example, shared book 
reading between children and adults, book-related activities such as taking trips to the library, and parental involvement in schoolwork related to reading have been shown to be positively associated with early reading skills (e.g., Bus \& Van Ijzendoorn, 1995;Foy \& Mann, 2003; Scarborough \& Dobrich, 1994;Senechal \& LeFevure, 2002). Parental modeling of literacy activities has also been associated with child reading skills (Taylor, 1983). In general, availability of books and other literacy materials in the home correlates approximately $r=.27$ with later reading success (Scarborough, 1998). In addition, there is also some evidence for a small to moderate effect of parental involvement upon individual differences in reading skills during primary and secondary school (e.g., Evans, 1998; Hewison \& Tizard, 1980;McDermott, Goldman, \& Varene, 1984;Sui, Esther, \& Wilms, 1996).

However, the studies described above have employed biologically related family members; consequently, they potentially confound genetic and environmental effects. By examining the relationship between measures of the environment and child outcomes within twin or adoption designs, it is possible to disentangle measures of the environment from the genetic variability in child outcomes and to know more decisively how much and in what ways children's literacy environment contributes to their achievements.

As an illustration, we examined this issue using three hundred fifty-four 4- to 13-year-old adopted children taking part in the Northeast-Northwest Collaborative Adoption Study (Petrill, Deater-Deckard, Schatschneider, \& Davis, 2005). Adoption designs provide the strongest test of the shared environment. Because adoptive children are genetically unrelated to their parents and siblings, correlations among outcomes are due to shared family experiences. Using these data, we found shared environmental mechanisms — children with more advanced phonological and orthographic skills as well as cognitive abilities had adoptive parents who were more involved in their children's schoolwork and who reported a richer literacy material in the home. In addition, these shared environmental influences increased in magnitude with development (Petrill et al., 2005). Other studies have found similar effects for chaos in the home predicting preschool cognitive skills (Petrill, Pike, Price, \& Plomin, 2004), as well as the effect of school environment and socioeconomic status on academic achievement (Walker, Petrill, \& Plomin, 2005).

Although this approach fits comfortably into the zeitgeist of social learning theory, quantitative genetic evidence presents a major challenge in that shared environment estimates drop to zero by adolescence in general cognitive ability (McGue et al., 1993) and even sooner for many measures of reading (Byrne et al., 2002). The most striking example is that adoptive children, as they get older, become less similar to their adoptive family members. However, they remain correlated with their biological family members despite a lack of shared family experiences (e.g., Plomin et al., 1997).

Another possibility is that genetic influences may have indirect effects through environments. In other words, environments are important to educational outcomes, but the probability of coming into contact with environments both positive and negative for educational development are influenced, in part, by genetic differences related to educational outcomes (see Figure 2). In this case, the intergenerational relationship between environments and outcomes is multidirectional and influenced, in part, by genetic similarity within the family.

Over the past two decades, behavioral genetic studies have highlighted the importance of these gene-environment processes, particularly when explaining the relationship between behavioral problems and parenting behavior. In an exceptional review of this literature, Moffitt (2005) describes how the field has progressively moved away from the view that parenting is the sole environmental cause of child behavior problems. Instead, this literature has embraced the idea that the relationship between parenting and child behavior is multidirectional and that 
this multidirectionality is influenced, in part, by genetic influences. In fact, this field is increasingly characterized by studies examining the relationship between behavioral problems, DNA markers, and measured environments (see Caspi et al., 2002) in order to outline the environmental contexts under which genetic risk is manifested in behavior problems.

The educational literature has many of the same components as the parenting literature: Complex behavioral outcomes that are genetically mediated, replicated DNA markers, and a rich literature describing environmental risk and protective factors related to development. Similar to the relationship between parenting and child behavior, some children develop educational problems in the absence of any known environmental risk, whereas other children thrive despite severe environmental privation. Unfortunately, the educational literature has yet to systematically take up the empirical study of how environmental risk translates into educational outcomes in the context of genetic risk. At their root, genetically sensitive designs suggest that family effects matter and these family effects impart risk for individual performance. Educational research has increasingly employed multilevel modeling approaches to examine the relationship between child performance nested within classrooms. However, because many of these studies are school based, they typically examine only one member of a family. It is therefore impossible to disentangle the potential impact of familial resemblance on variability in educational outcomes in the context of these other predictors. This is not to suggest that every educational study involve twins or DNA markers, but including multiple family members would provide a way to treat family-level variance as a fixed effect and may open up interesting avenues for more detailed genomic research on those child outcomes that are influenced by Family $\times$ Classroom or Family $\times$ School interactions.

Additionally, genetically sensitive and genetically consistent designs also present important opportunities for intervention research conducted in classrooms and schools. Currently, this literature is characterized by experimental designs where mean effects of intervention are assessed for children who are nested within schools and classrooms. These studies typically concentrate on the mean effects of the intervention but not much is known about children's variability in response to the intervention. Nonetheless, educational researchers today are becoming increasingly concerned about the prevalence of treatment resistance, that is, a child's lack of response to a particular educational intervention. The extent to which responsiveness to prereading interventions varies for specific subgroups of children has historically received little attention, although this topic is of increasing interest in the field of reading research (e.g., Fuchs et al., 2002; Vaughn, Linan-Thompson, \& Hickman, 2003). As Fuchs and colleagues note (p. 307), if we are to take the perspective that "all children count," then intervention researchers must increasingly contend with the fact that a substantial number of children will not respond adequately to systematic and empirically validated interventions.

Given the quantitative and molecular genetic evidence described above, it is possible, even likely, that genetic differences explain a proportion of variability in intervention responsiveness. Several possible approaches may be brought to bear upon this issue. As described earlier in this review, quantitative genetic studies clearly show comorbidity for learning problems. To what extent do family remembers show similar responses to remedial services and to what extent do identical twins show more similarity in response than fraternal twins? From a molecular genetic perspective, are children with particular patterns of genetic risk more or less likely to respond favorably to a particular intervention, and more provocatively, is that response further mediated or moderated by the presence or absence of other environmental risk factors? 


\section{CHALLENGES}

Despite these possibilities to better understand educational outcomes and educational practices, there are significant challenges ahead. The literatures of genetics, social learning theory, neurobiology, the measurement and assessment of complex educational outcomes, and educational practices are rapidly evolving fields with many very basic unanswered questions. For example, reading disability remains the "best case" example of molecular genetic success for educational outcomes. However, finding DNA polymorphisms that explain a significant portion of the $h^{2}$ of reading has remained elusive, despite significant technological advances in the search for DNA markers. Fortunately (or unfortunately), reading is not alone. Consider Alzheimer's disease that appears to divide into two subtypes influenced by different genetic mechanisms. Early-onset Alzheimer's appears to be influenced by a handful of rare genes that are large in effect size. Late-onset Alzheimer's is more common, is highly heritable, and appears to be best understood as arising from a number of genes that operate in a probabilistic manner. The emergence of the APOE-4 allele (e.g., Rao et al., 1996) touched off a firestorm of publications in leading medical journals. One review examined 91 published studies in 2003 and found that, aside from the well-replicated APOE-4 finding, only 3 loci were replicated out of 127 reported associations (Bertram \& Tanzi, 2004).

As a result of this example and others, genetics is currently involved in a field-wide transformation in the understanding of genetic influence on complex outcomes (Botstein \& Risch, 2003; Glazer, Nadeua, \& Aitman, 2002). For example, research has suggested that mildly deleterious mutations have aggregated in the human population (Prichard, 2001). These mutations are similar to the major genes in the sense that they are relatively rare but different in that these mutations are small in effect. Recent analyses using publicly available genome banks suggest that around 53\% of mutations in the human genome may be rare but mildly deleterious (Kryukov, Pennachio, \& Sunyaev, 2007). Because of this and other examples, molecular genetics and statistical genetics are currently engaged in theoretical and empirical discussions of how this potential mechanism fits into the major gene-versus-common-variant dichotomy that has dominated the field for the past 15 years. The point of this example is not to suggest that genetic research in education is premature. Instead, genetics, like education, is a nuanced, complex, and evolving field. Behavioral scientists often view genetics methods as a fancy search engine with fully known entries and known search procedures. In the same way, geneticists often oversimplify the measurement and developmental trajectory of phenotypes and environmental measures. Truly interdisciplinary research can begin only when these kinds of oversimplifications are minimized.

Additionally, genetically sensitive designs, particularly those used in education, have to swim upstream against a historical record sometimes punctuated by overinterpretation of the data and attempts to use genetic information as a veridical predictor of academic success and future learning potential. Again, all the available evidence suggests that genes operate as risk factors across a continuum of effect size. Coupled with all of the unstudied potential interactions between genetics and environmental risk, even assuming perfect measurement, there is virtually no chance that DNA markers in childhood can predict adult educational outcomes in anything approaching a deterministic manner. However, given the history, there remains a latent fear that these data may be used, even erroneously, to limit opportunity. Thus, the empirical study of genetics and education is tied to the ethical issues related to genetics, which is also a nuanced field of study.

\section{CONCLUSIONS}

Do the potential benefits of combining genetically sensitive designs and education offset the considerable empirical and societal challenges? Taking reading as an example, over the past 
25 years, there has been important progress in our understanding of the components that shape individual differences in reading skills. The role of phonological awareness, sound-letter correspondence, vocabulary, and reading fluency has been well established (see National Institute of Child Health and Human Development, 2000; Whitehurst \& Lonigan, 1998). Despite these advances, the National Assessment of Educational Progress (NAEP, 2003) reported that $37 \%$ of fourth- and $26 \%$ of eighth-grade children failed to achieve "basic" levels of reading comprehension proficiency and less than half of these children achieve higher levels of comprehension proficiency required for success in technical or scientific careers (see http://nces.ed.gov/nationsreportcard/pdf/main2003/2004452. pdf). Although statistically significant reductions in the incidence of reading difficulties in fourth and eighth grade have been reported by NAEP since 1998, the effect size of these mean changes has been small, in the magnitude of a few percentage points, ensconced by considerable within-group variability. This picture is even more striking for math difficulties. The bottom line is that we are far from understanding why some children thrive despite privation and other children demonstrate learning problems despite environmental enrichment. Genetically sensitive designs suggest strongly that genetic variability cannot be ignored as we search for the answer to this important question. Furthermore, these designs suggest that genetics may play an important role in the considerable comorbidity among multiple domains of academic performance and also suggest that disability is largely the quantitative tail of ability. While we should be under no illusions concerning the difficulty of this endeavor, like other epidemiological, biobehavioral outcomes such as obesity, cardiovascular health, substance abuse, and mental health, including genetically sensitive designs into the science of education offers the potential to better quantify the effects of individual, family, proximal, and distal factors in development.

\section{References}

Amir RE, Van den Veyver IB, Wan M, Tvan CQ, Franke U, Zoghbi HY. Rett syndrome is caused by mutation in X-linked MECP2, encoding methyl-CpG-binding protein 2. Nature Genetics 1999;12:185188. [PubMed: 10508514]

Bartels M, Rietveld MJH, Van Baal GCM, Boomsma DI. Genetic and environmental influences on the development of intelligence. Behavior Genetics 2002;32:237-249. [PubMed: 12211623]

Bertram L, Tanzi RE. Alzheimer's disease: One disorder, too many genes? Human Molecular Genetics 2004;13:R135-R141. [PubMed: 14764623]

Bishop DVM. What causes specific language impairment in children? Current Directions in Psychological Science 2006;15:217-221. [PubMed: 19009045]

Bishop, EG.; Cherny, SS.; Hewitt, JK. Developmental analysis of IQ. In: Petrill, SA.; Plomin, R.; DeFries, JC.; Hewitt, JK., editors. Nature, nurture, and the transition to early adolescence. New York: Oxford University Press; 2003. p. 13-27.

Boomsma, D. Current status and future prospects in twin studies of the development of cognitive abilities: Infancy to old age. In: Bouchard, TJ., Jr; Propping, P., editors. Twins as a tool of behavioral genetics. Chichester, UK: Wiley; 1993. p. 67-82.

Botstein D, Risch N. Discovering genotypes underlying human phenotypes: Past successes for Mendelian disease, future approaches for complex disease. Nature Genetics 2003;33:228-237. [PubMed: 12610532]

Bouchard JT Jr, McGue M. Familial studies of intelligence: A review. Science 1981;212:1055-1059. [PubMed: 7195071]

Briggs C, Elkind D. Characteristics of early readers. Perceptual and Motor Skills 1977;44:1231-1237.

Bus AG, van IJzendoorn MH. Phonological awareness and early reading: A meta-analysis of experimental training studies. Journal of Educational Psychology 1995;91:403-414.

Byrne B, Delaland C, Fielding-Barnsley R, Quain P, Samuelsson S, Hoien T, et al. Longitudinal twin study of early reading development in three countries: Preliminary results. Annals of Dyslexia 2002;52:49-74. 
Byrne B, Wadsworth S, Corley R, Samuelsson S, Quain P, DeFries JC, et al. Longitudinal twin study of early literacy development: Preschool and kindergarten phases. Scientific Studies of Reading 2005;9:219-236.

Caspi A, McClay J, Moffitt T, Mill J, Martin J, Craig IW, et al. Role of genotype in the cycle of violence in maltreated children. Science 2002;297:851-854. [PubMed: 12161658]

Centers for Disease Control. CDC releases new data on Autism Spectrum Disorders (ASDs) from multiple communities in the United States. 2007. Retrieved February 15, 2007, from http://www.cdc.gov/od/oc/media/pressrel/2007/r070208.htm

Cherny SS, Fulker DW, Emde RN, Robinson J, Corley RP, Reznick JS, et al. A developmental genetic analysis of continuity and change in the Bayley mental development index from 14 to 24 months: The MacArthur longitudinal twin study. Psychological Science 1994;5:354-360.

Chipuer HM, Rovine MJ, Plomin R. LISREL modeling: Genetic and environmental influences on IQ revisited. Intelligence 1990;14:11-29.

Christian K, Morrison FJ, Bryant FB. Predicting kindergarten academic skills: Interactions among child care, maternal education, and family literacy environments. Early Child Research Quarterly 1998;13:501-521.

Compton, DL.; Davis, CJ.; DeFries, JC.; Gayan, J.; Olson, RK. Genetic and environmental influences on reading and RAN: An overview of results from the Colorado twin study. In: Wolf, M., editor. Conference proceedings of the dyslexia research foundation conference in extraordinary brain series: Time, fluency, and developmental dyslexia. Baltimore: York Press; 2001. p. 277-303.

Davis CJ, Knopik VS, Olson RK, Wadsworth SJ, DeFries JC. Genetic and environmental influences on rapid naming and reading ability: A twin study. Annals of Dyslexia 2001;51:231-247.

DeFries JC, Fulker DW. Multiple regression analysis on twin data. Behavior Genetics 1985;15:467-473. [PubMed: 4074272]

DeFries JC, Fulker DW. Multiple regression analysis of twin data: Etiology of deviant scores versus individual differences. Acta Geneticae Medicae et Gemellologicae 1988;37:205-216.

Dunn NE. Children's achievement at school-entry age as a function of mothers' and fathers' teacher sets. Elementary School Journal 1981;81:245-253.

Erlenmeyer-Kimling L, Jarvik LF. Genetics and intelligence: A review. Science 1963 December 13;142:1477-1479. [PubMed: 14077032]

Evans MA. Parental involvement in beginning reading: Preliminary report from a three-year longitudinal study. Canadian Journal of School Psychology 1998;14:11-20.

Fisher SE, DeFries JC. Developmental dyslexia: Genetic dissection of a complex cognitive trait. Nature Reviews Neuroscience 2002;3:767-780.

Foch TT, DeFries JC, McClearn GE, Singer SM. Familial patterns of impairment in reading disability. Journal of Educational Psychology 1977;69:316-329. [PubMed: 893770]

Foy JG, Mann V. Home literacy environment and phonological awareness in preschool children: Differential effects for rhyme and phoneme awareness. Applied Psycholinguistics 2003;24:59-68.

Fuchs LA, Fuchs D, Speece DL. Treatment validity as a unifying construct for identifying learning disabilities. Learning Disability Quarterly 2002;25:33-45.

Fulker, DW.; Cherny, SS.; Cardon, LR. Continuity and change in cognitive development. In: Plomin, R.; McClearn, GE., editors. Nature, nurture \& psychology. Washington, DC: American Psychological Association; 1993. p. 77-97.

Galton, F. Heredity, genius: An enquiry into its laws and consequences. London: Macmillan; 1869.

Gayan J, Olson RK. Genetic and environmental influences on orthographic and phonological skills in children with reading disabilities. Developmental Neuropsychology 2001;20:487-511.

Gayan J, Olson RK. Genetic and environmental influences on individual differences in printed word recognition. Journal of Experimental Child Psychology 2003;84:97-123. [PubMed: 12609495]

Glazier AM, Nadeau JH, Aitman TJ. Finding genes that underlie complex traits. Science 2002;20:23452349. [PubMed: 12493905]

Guo G, Wang J. The mixed or multilevel model for behavior genetic analysis. Behavior Genetics 2001;32:37-49. [PubMed: 11958541] 
Harlaar N, Spinath FM, Dale PS, Plomin R. Genetic influences on early word recognition abilities and disabilities: A study of 7-year-old twins. Journal of Child Psychology and Psychiatry 2005;46:373384. [PubMed: 15819646]

Haworth CA, Kovas Y, Petrill SA, Plomin R. Developmental origins of low mathematics performance and normal variation in twins from 7 to 9 years. Twin Research and Human Genetics 2007;10:106117. [PubMed: 17539370]

Hewison J, Tizard J. Parental involvement and reading attainment. British Journal of Educational Psychology 1980;50:209-215. [PubMed: 7437294]

Knopik VS, Alarcón M, DeFries JC. Common and specific gender influences on individual differences in reading performance: A twin study. Personality and Individual Differences 1998;25:269-277.

Kovas Y, Harlaar N, Petrill SA, Plomin R. 'Generalist genes' and mathematics in 7-year-old twins. Intelligence 2005;33:473-490. [PubMed: 19319204]

Kovas Y, Petrill SA, Haworth C, Plomin R. The origins of mathematical ability and disability: 10 yearold twins. Journal of Learning Disabilities. in press

Kryukov GV, Pennacchio LA, Sunyaev SR. Most rare missense alleles are deleterious in humans: Implications for complex disease and association studies. American Journal of Human Genetics 2007;80:727-739. [PubMed: 17357078]

Lejuene J, Gautier M, Turpin R. Etudes des chromsomes somatiques de neuf enfants mongoliene. Canadian Royal Academy of Sciences 1959;248:1721.

Matheny AP Jr, Dolan AB, Wilson RS. Twins with academic learning problems: antecedent characteristics. American Journal of Orthopsychiatry 1976;46:464-469. [PubMed: 945944]

McCardle P, Scarborough HS, Catts HW. Predicting, explaining, and preventing children's reading difficulties. Learning Disabilities Research \& Practice 2001;16:230-239.

McCartney K, Harris MJ, Bernieri F. Growing up and growing apart: A developmental meta-analysis of twin studies. Psychological Bulletin 1990;107:226-237. [PubMed: 2138795]

McDermott RP, Goldman SV, Varenne H. When school goes home: Some problems in the organization of homework. Teachers College Record 1984;85:391-409.

McGue, M.; Bouchard, TJ., Jr; Iacono, WG.; Lykken, DT. Behavioral genetics of cognitive ability: A lifespan perspective. In: Plomin, R.; McClearn, GE., editors. Nature, nurture, and psychology. Washington, DC: American Psychological Association; 1993. p. 59-70.

Moffitt TE. The new look of behavioral genetics in developmental psychopathology: Gene-environment interplay in antisocial behaviors. Psychological Bulletin 2005;131:533-554. [PubMed: 16060801]

Molfese D, Molfese V, Key AF, Kelly S. Influence of environment on speech-sound discrimination: Findings from a longitudinal study. Developmental Neuropsychology 2003;24:541-558. [PubMed: 14561561]

National Assessment of Educational Progress. Reading: Student background questionnaire. 2003. Retrieved October 1, 2003, from http://nces.ed.gov/nationsreportcard/pdf/bgg/student/reading/y1br1.pdf

National Institute of Child Health and Human Development. Teaching children to read: An evidencebased assessment of the scientific research literature on reading and its implications for reading instruction: Reports of the subgroups (Report of the National Reading Panel, NIH Publication No. 00-4754). Washington, DC: U.S. Government Printing Office; 2000.

Olson, RK.; Forsberg, H.; Wise, B. Genes, environment, and the development of orthographic skills. In: Berninger, VW., editor. The varieties of orthographic knowledge I: Theoretical and developmental issues. Dordrecht, The Netherlands: Kluwer Academic Publishers; 1994. p. 27-71.

Olson RK, Gillis JJ, Rack JP, DeFries JC, Fulker DW. Confirmatory factor analysis of word recognition and process measures in the Colorado Reading Project. Reading and Writing 1991;3:235-248.

Orton ST. "Word-Blindness" in School Children. Archives of Neurology and Psychiatry 1925;1925:581615.

Petrill, SA. The development of intelligence: Behavioral genetic approaches. In: Sternberg, R.; Lautrey, J.; Lubart, T., editors. Models of intelligence: International perspecitves. Washington, DC: American Psychological Association; 2003. p. 81-90.

Petrill SA, Deater-Deckard K, Schatschneider C, Davis C. Measured environmental influences on early reading: Evidence from an adoption study. Scientific Studies of Reading 2005;9:237-260. 
Petrill SA, Deater-Deckard K, Thompson LA, DeThorne LS. Reading skills in early readers: Genetic AND shared environmental influences. Journal of Learning Disabilities 2006;39:48-55. [PubMed: 16512082]

Petrill SA, Deater-Deckard K, Thompson L, Schatschneider C, DeThorne L. Longitudinal genetic analysis of early reading: The Western Reserve Reading Project. Reading and Writing 2007;20:127246. [PubMed: 19829751]

Petrill SA, Lipton PA, Hewitt JK, Cherny SS, Plomin R, Corley R, et al. Genetic and environmental contributions to general cognitive ability through the first 16 years of life. Developmental Psychology 2004;40:805-812. [PubMed: 15355167]

Petrill SA, Pike A, Price T, Plomin R. Chaos in the home and socioeconomic status are associated with cognitive development in early childhood: Environmental risks identified in a genetic design. Intelligence 2004;32:445-460.

Petrill, SA.; Plomin, R. Quantitative genetics and mathematical abilities/disabilities. In: Berch, D.; Mazzocco, M., editors. Mathematical learning disabilities: Research, theory, and practice. Baltimore: Brookes Publishing; 2007. p. 307-324.

Petrill SA, Saudino KJ, Cherny SS, Emde RN, Hewitt JK, Fulker DW, et al. Exploring the genetic etiology of low general cognitive ability from 14 to 36 months. Developmental Psychology 1997;33:544548. [PubMed: 9149933]

Plomin R. Multivariate analysis and developmental behavioral genetics: Developmental change as well as continuity. Behavior Genetics 1986;16:25-43. [PubMed: 3707486]

Plomin R, DeFries JC. Multivariate behavioral genetic analysis of twin data on scholastic abilities. Behavior Genetics 1979;9:505-517. [PubMed: 263636]

Plomin, R.; DeFries, JC.; McClearn, GE.; McGuffin, P. Behavioral genetics. Vol. 4. New York: Worth Publishers; 2001.

Plomin R, Fulker DW, Corley R, DeFries JC. Nature, nurture, and cognitive development from 1 to 16 years: A parent-offspring adoption study. Psychological Science 1997;8:442-447.

Plomin R, Kovas Y. Generalist genes and learning disabilities. Psychological Bulletin 2005;131:592617. [PubMed: 16060804]

Plomin R, Kovas Y, Haworth CMA. Generalists genes: Genetic links between mind, brain, and education. Mind, Brain, and Education 2007;1:11-19.

Plomin R, Owen MJ, McGuffin P. The genetic basis of complex human behaviors. Science 1994;264:1733-1739. [PubMed: 8209254]

Plomin R, Spinath FM. Intelligence: genetics, genes, and genomics. Journal of Personality and Social Psychology 2004;86:112-129. [PubMed: 14717631]

Plomin, R.; Thompson, LA. Genetics and high cognitive ability. In: Book, GR.; Ackrill, K., editors. The origins and development of high ability. Chichester, UK: Wiley (Ciba Foundation Symposium 178); 1993. p. 67-84.

Pritchard JK. Are rare variants responsible for susceptibility to complex diseases? American Journal of Human Genetics 2001;69:124-137. [PubMed: 11404818]

Rao VS, Cupples A, van Duijn CM, Kurz A, Green RC, Chui H, et al. Evidence for major gene inheritance of Alzheimer disease in families of patients with and without apolipoprotein E epsilon 4. American Journal of Human Genetics 1996;59:664-675. [PubMed: 8751868]

Rescorla L, Hyson M, Hirsh-Pasek K, Cone J. Academic expectations in mothers of preschool children. Early Education and Development 1990;1:165-184.

Saudino KJ, Plomin R, Pedersen NJ, McClearn GE. The etiology of high and low cognitive ability during the second half of the life span. Intelligence 1994;19:359-371.

Scarborough, HS. Early identification of children at risk for reading disabilities: Phonological awareness and some other promising predictors. In: Shapiro, BK.; Accardo, PJ.; Capute, AJ., editors. Specific reading disability: A view of the spectrum. Timonium, MD: York Press; 1998. p. 75-119.

Scarborough HS, Dobrich W. On the efficacy of reading to preschoolers. Developmental Review 1994;14:245-302.

Senechal M, LeFevure J. Parental involvement in the development of children's reading skills: A fiveyear longitudinal study. Child Development 2002;73:445-460. [PubMed: 11949902] 
Stevenson J, Graham P, Fredman G, McLoughlin V. A twin study of genetic influences on reading and spelling ability and disability. Journal of Child Psychology and Psychiatry 1987;28:229-247. [PubMed: 3584294]

Sui C, Esther H, Willms JD. Effects of parental involvement on eighth-grade achievement. Sociological Quarterly 1996;69:126-141.

Taylor, D. Family literacy: Young children learning to read and write. Exeter, NH: Heineman; 1983.

Vaughn S, Linan-Thompson S, Hickman P. Response to instruction as a means of identifying students with reading/learning disabilities. Exceptional Children 2003;69:391-409.

Wadsworth SJ, Corley RP, Hewitt JK, Plomin R, DeFries JC. Parent-offspring resemblance for reading performance at 7,12 and 16 years of age in the Colorado Adoption Project. Journal of Child Psychology and Psychiatry and Allied Disciplines 2002;43:769-774.

Walker SA, Petrill SA, Plomin R. A genetically sensitive investigation of the effects of the school environment and socio-economic status on academic achievement in 7-year-olds. Educational Psychology 2005;25:55-73.

Whitehurst GJ, Lonigan CJ. Child development and emergent literacy. Child Development 1998;68:848872. [PubMed: 9680688]

Wilson RS. The Louisville twin study: Developmental synchronies in behavior. Child Development 1983;54:298-316. [PubMed: 6683617]

Zechner U, Wilda M, Kehrer-Sawatzki H, Vogel W, Fundele R, Hameister H. A high density of X-linked genes for general cognitive ability: A runaway process shaping human evolution? Trends in Genetics 2001;17:697-701. [PubMed: 11718922]

Zerbin-Rüdin E. Congenital word-blindness. Bulletin of the Orton Society 1967;17:47-56.

Zigler, E.; Hodnapp, RM. Understanding mental retardation. New York: Cambridge University Press; 1986. 


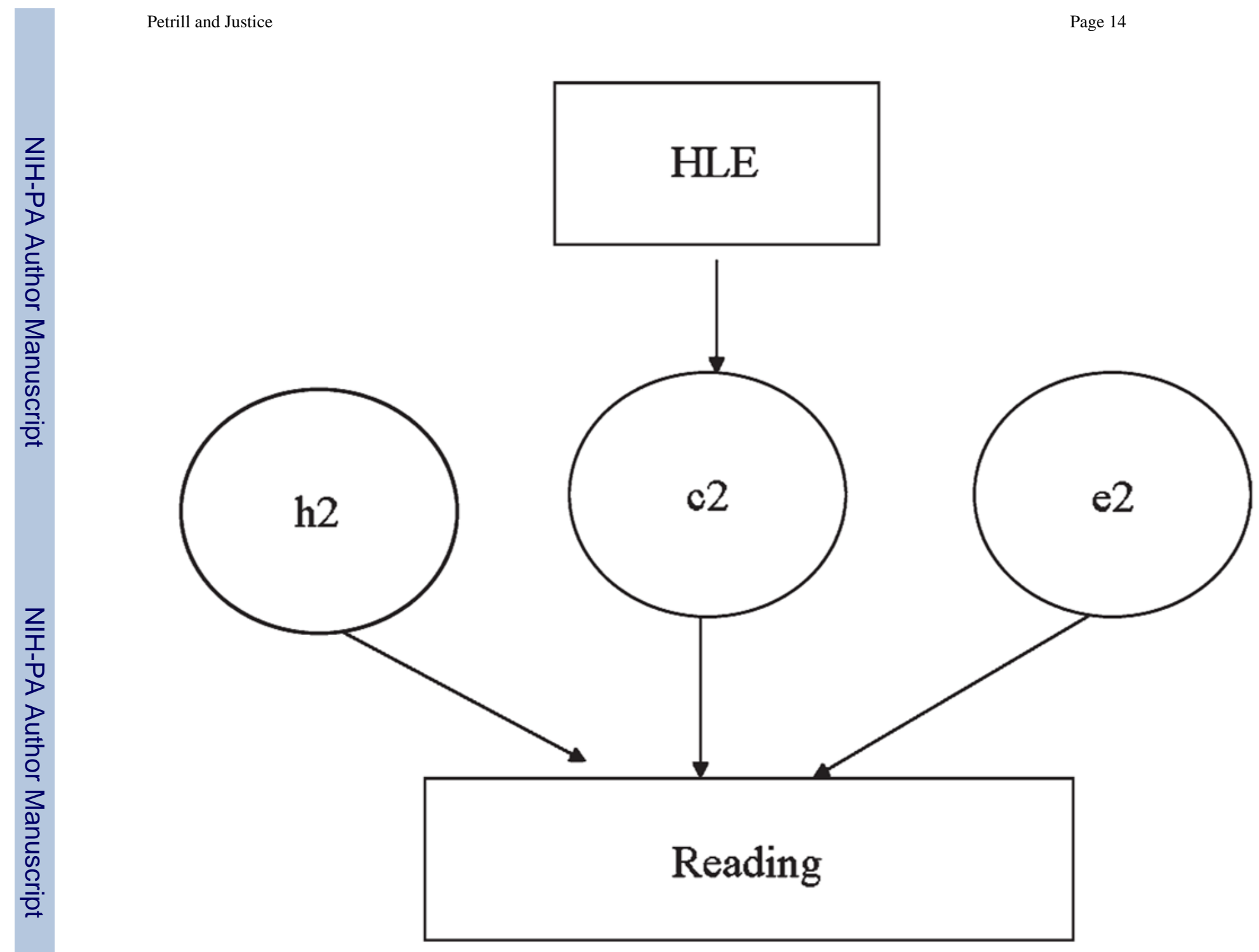

Fig. 1.

Direct effects model of the environment. 


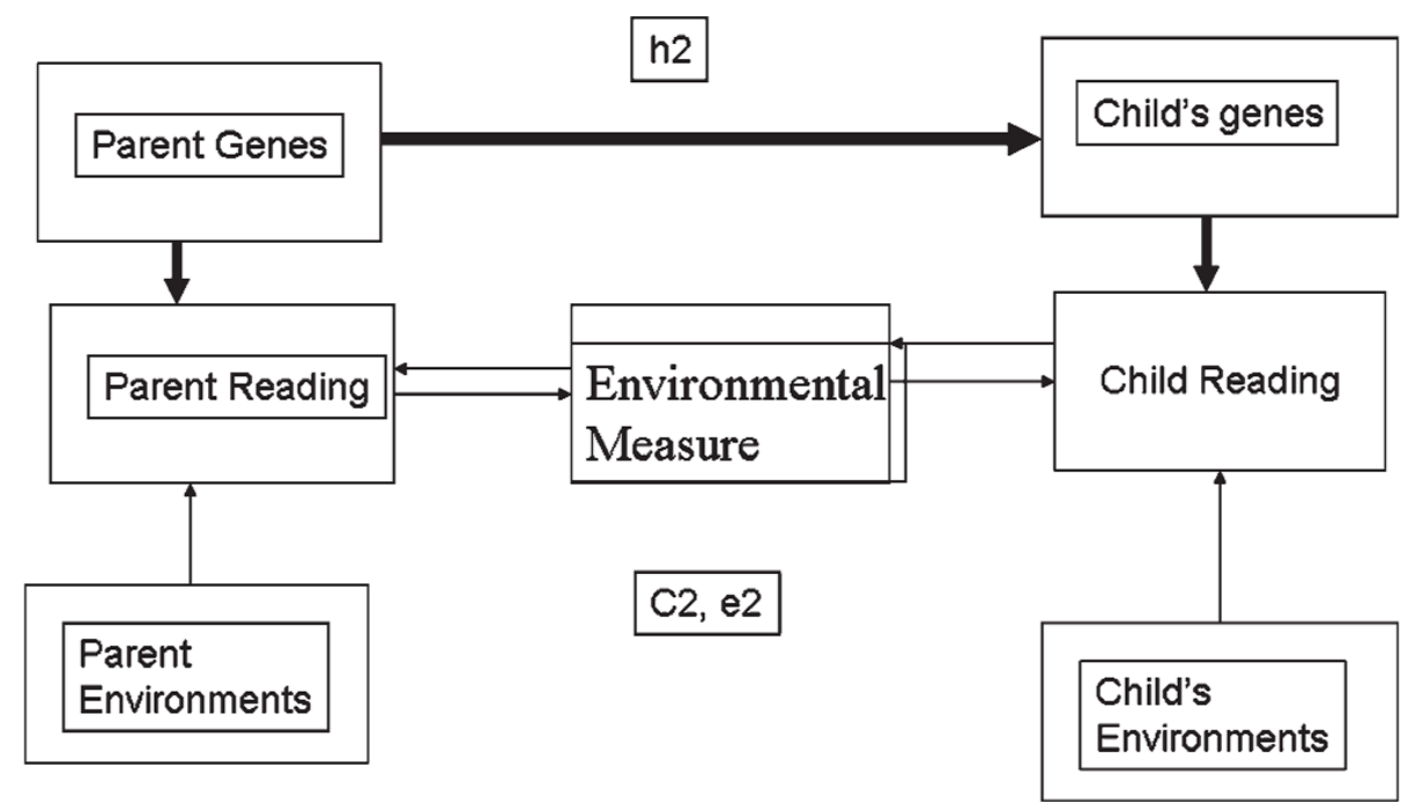

Fig. 2.

Gene-environment model. 